\title{
MICROBIAL DEGRADATION OF ANCIENT TEXTILES HOUSED IN THE EGYPTIAN TEXTILE MUSEUM AND METHODS OF ITS CONTROL
}

\author{
Omar, A. ${ }^{1}$, Taha, A. ${ }^{2(*)} \&$ El-Wekeel, F. ${ }^{3}$ \\ ${ }^{I}$ Conservator, Conservation Center, Grand Egyptian Museum, Egypt \\ ${ }^{2}$ Conservation dept., Faculty of Archaeology, Aswan Univ., Aswan, Egypt \\ ${ }^{3}$ Conservator, El-Manial Palace Museum, Supreme Council of Antiquities, Cairo, Egypt \\ E-mail: aymansalahtaha82@yahoo.com
}

\begin{abstract}
All ancient textile materials have a simple chemical composition, mainly cellulose and protein. This organic component increases the susceptibility of textiles to soaking up and retaining wet from the unfavorable conditions of high humidity and temperature, causing microbial deterioration. Microbial deterioration of archaeological textile was studied as a state from the Egyptian Textile Museum; isolation, purification, and identification of the causative microorganisms were occurring, where the most common microorganisms isolated from archaeological textiles were molds. Biological activities of the isolated microorganisms were studied and disinfection of archaeological textile was applied using different methods. The characteristics of test methods and disinfection include their application to historical objects. Historic textiles were analyzed from different perspectives: Stereo microscopes, SEM with EDX, FTIR, as well as fiber structure and fiber chemical composition. The results illustrated that the best concentrations of a specific mic-robicide for the bio-treatment of infected textile materials is Di-chloroxylenol at (1000 ppm). It is sufficient to inhibit all isolated microorganisms, followed by p-chloro-m-cresol at (1000 ppm) concentration, and Sodium azide at (2000 ppm) concentration.
\end{abstract}

Keywords: Textiles, Microbial, Antimicrobial agents, Enzymes, Biocides treatments

\section{Introduction}

The deterioration process includes any undesirable change in the properties of the material caused by the vital activities of organisms [1]. It mainly depends on the type and origin of fabric, contact with microorganisms or insects, and storage conditions (temperature, humidity, light, oxygen, dust, and pollution). Antique textile objects are an important part of the cultural heritage that needs to be maintained. However, preserving them for a long time is a real challenge not only for conservators and museum staff, but for microbiologists, chemists, textile scientists, and other experts, as well. Recently, it's generally agreed that fungi and bacteria not only cause serious aesthetic destruction of paintings, costumes, ceramics, mummies, books, and manuscripts, but they inhabit and penetrate into the materials, leading to material loss owing to acid corrosion, enzymatic degradation, and physical alteration. Moreover, the decontamination of the infected artifacts, exhibition rooms, and depots could lead to high expenditure for museums [1-3]. Fungi and bacteria cause serious damage to historic materials as a result of secreting organic acids and specific enzymes such as cellulose, protease and ligninases [4]. During the 
deterioration of textiles, microorganisms produce extracellular cellulolytic and proteolytic enzymes as well as secreting pigments and acids. The deterioration of textiles leads to odors, staining, discoloration, a decrease in strength, and a change in $\mathrm{pH}$. [1,5]. Stains appear due to the action of exo-pigments, which are secreted by microbial cells and diffuse into the fabric. The ability of textiles to absorb and retain moisture from the surrounding environment in the museums, coupled with their organic components, makes them highly susceptible to fungal deterioration. Advanced changes to the properties of textile materials are commonly done by the natural ageing that causes historical textiles to become more susceptible to microbial deterioration [6-8]. The present study isolated the fungi deteriorating historical

\section{Material and Methods}

\subsection{Sampling}

Microbial swabs were taken from six showcases $(14,28,30,31,133 \&$ 144) at the Egyptian Textile Museum. This process was done through scratching the surface of the infected materials by sterilized cotton swabs and transferred directly into four prepared agar media (Cellulose agar, Gelatin agar, Dox agar,

\subsection{Media}

The media used in this study can be summarized, as follows: List of media used for growth, preservation or identification of microbial isolates obtained from

\subsubsection{Productive medium}

According to Ammar, et al., [11], the medium listed in tab. (1) was used for the production of cellulose and protease enzymes. The main source of carbon textiles at the Egyptian and the Coptic Mus-eums in Cairo and found out that the most dominant fungi species belong to Alternaria, Aspergillus, Chaetomium, Penicillium and Trichoderma. The storage conditions and contact of textiles with microorganisms are also important to be investigated. The examples reported in literatures indicate that archaeological textiles that have permanent contact with water and soil (historical textile objects, e.g. mummies, textiles in the graves, tombs, crypts, sunken ships, and soldier's uniforms) are more susceptible to deterioration. Such susceptibility also depends on the degree of polymerization and crystallinity of the polymer fibers; the fabric thickness and the type of weave [6].

and Nutrient agar). Plates were incubated at $28-30^{\circ} \mathrm{C}$ for $1-7$ days depending on the microorganism. At the same time, air samples of showcases were taken from the surface of the same media to be compared to the results of the swabs.

the samples: Dox agar medium, Gelatin agar medium, Cellulose agar medium and Nutrient agar medium. Media used to enzymes productivity $[9,10]$.

(sucrose) was replaced with $10 \mathrm{~g}$ of cellulose and $10 \mathrm{~g}$ of gelatin. It is composed of the following ingredients:

Table (1) Productive medium used for the production of cellulose and protease enzymes

\begin{tabular}{lcc}
\hline & Ingredient & g/L \\
\hline $\mathrm{NaNO}_{3}$ & 2.0 \\
$\mathrm{KH}_{2} \mathrm{PO}_{4}$ & 1.0 \\
$\mathrm{MgSO}_{4} \cdot 7 \mathrm{H}_{2} \mathrm{O}$ & 0.5 \\
$\mathrm{KCl}$ & 0.5 \\
$\mathrm{FeSO}$ & $7 \mathrm{H}_{2} \mathrm{O}$ & 0.01 \\
$\mathrm{Sucrose}$ & 20 \\
Distilled water & $1 \mathrm{~L}$ \\
\hline $\mathrm{pH}$ & $6.5-7$ \\
\hline
\end{tabular}




\subsubsection{Detection medium}

As have been mentioned by Ammar, et al., [12] the detection medium was proteolysis isolates. It is composed maiused for the selection of cellulolytic and nly of the ingredients listed in tab. (2):

Table (2) Detection medium used for the selection of cellulolytic and proteolysis isolates

\begin{tabular}{lc}
\hline \multicolumn{1}{c}{ Ingredient } & $\mathbf{g L}^{-1}$ \\
\hline Arabic gum & 2.0 \\
Agar & 15.0 \\
Cellulose powder (for cellulose activity) & 10.0 \\
Gelatin powder (for protease activity) & 10.0 \\
Distilled water & $1000 \mathrm{ml}$ \\
\hline $\mathrm{pH}$ & 7.0 \\
\hline
\end{tabular}

\subsection{Identification of microbial isolates}

The identification of all microbial isolates was carried out at the Lab. of Microbiology, Conservation Center, Grand Egyptian Museum. Colonies grown in the media (Cellulose agar, Gelatin agar, Dox agar, and Nutrient agar). Plate's media were purified on the same medium. Each single colony was picked for identification according to [13-15] by determining the morphological characteristics using Carl Zies light microscope attached to an analysis unit and a digital camera, then they were compared with the references standard.

\subsection{Determination of cellulose and protease activity of the isolated micro- organisms}

\subsubsection{Enzyme production}

Production was carried out in 250 ml. conical flasks. Each one contains 100 $\mathrm{ml}$. of the production medium (for the production of cellulose and protease enzymes. The main source of carbon (sucrose) was replaced with $10 \mathrm{~g}$ of cellulose and $10 \mathrm{~g}$ of gelatin, respectively). Flasks were sterilized at $121^{\circ} \mathrm{C}$ for $15 \mathrm{~min}$. After cooling, they were inoculated with $2 \mathrm{ml}$. of standard

\subsubsection{Enzyme assay}

Cup plate clearing zone technique (CCZ) was used for assaying the activities of cellulase and protease enzymes. It was carried out by pouring $20 \mathrm{ml}$. aliquots of the detection medium [11] into a sterile Petri dish and allowed to solidify. A sterile corn borer $(15 \mathrm{~mm}$ diameter) was used to make three cups in each plate and 0.1 $\mathrm{ml}$ of the supernatant (cell-free enzyme) of each isolate was placed into the three

\subsection{Determination of minimal inhibitory concentration (MIC) of antimicrobial agents against the isolated microorganisms}

Three commercially available microcides were purchased from Aldrich Company (Germany) and tested against the isolated microorganisms to determine their MICs. They were Di-chloroxylenol, Sodium acid, and p-chloro-m-cresol. A stock solution of each microcide was prepared by inoculum of each isolate. The inoculated flasks were incubated at $28-30{ }^{\circ} \mathrm{C}$ for proper time. At the end of the incubation period, the liquid cultures were centrifuged at 3000 RPM for 15 minutes. The supernatant was taken for the determination of enzyme (cellulases and protease) activity, as described below.

cups. The plates were incubated at $30^{\circ} \mathrm{C}$ for $24 \mathrm{~h}$. Then, they were flooded with a Lugol's iodine solution to assay cellulose and an acid mercuric chloride solution to assay protease. Enzyme activities were compared based on the diameter ( $\mathrm{mm}$ ) of the clear zone. Isolates showing the highest activity for each enzyme were used in the subsequent experiments.

dissolving $1 \mathrm{~g} / \mathrm{L}$ ethyl alcohol (95\%). Gradient concentrations of each microcode (from 900 to 3000 p.m.) were prepared by diluting the stock solution with alcohol. $1 \mathrm{ml}$ of spore suspension was spread on Dox agar plate. The plates were allowed to dry, then a cork purer was used to 
make three pores in each plate. On one plate, $100 \mu \mathrm{l}$ of each concentration (from 900 to 3000 p.m.) of the tested microcides were placed in each pore. The plates were incubated at $30{ }^{\circ} \mathrm{C}$ for $1-3$ days compared with control plates (ethyl alcohol instead of microcides). The MIC was determined by measuring the inhibition zone according to Brantner, et al., [16]. MIC test is the gold standards for deciding the susceptibility of organisms to a specific antimicrobial substance so accustomed decide the performance of all different strategies of susceptibility testing [17].

\subsection{Effect of microcides on infected textile}

In this experiment, the modern pieces of textile (modern linen samples; measured $10 \mathrm{~cm} \times 10 \mathrm{~cm}$, weighted $3 \mathrm{~g}$., colored beige and collected from the Textile Company in Mahalla, Egypt) were infected with the isolated microorganisms, incubated for two months at room temperature. After the end of the incubation

\section{Results}

\subsection{Microbial isolates}

According to Ammar, et al. [12] and Gilman [13] the resulted microbial colonies subjected to preliminary characterization depending on the type of organism and their morphology proved that there are three main genera were identified: Aspergillus, Cladosporium and Pacillomyces, as listed in tab. (3) \& shown in fig. (1). In this regard, it can be seen that the genus Pacillomyces carneus was dominant in the six showcases of the total fungal isolates, followed by Aspergillus period, the pieces of textile were treated with the best microcides. Then the effect of microcides on textile was determined using Binocular dissecting stereomicrooscope, FTIR (Fourier Transform Infrared), in addition to environmental scanning electron microscope (ESEM).

and Cladosporium. In addition, the species of Pacillomyces isolated from all showcases indicate that the spores of its microorganisms were present in all showcases and caused the infection to the pieces of textile. In addition, the environmental condition inside and outside the showcases were suitable for microbial growth. They were recorded inside the showcases as 26 ${ }^{\circ} \mathrm{C}$ and $74 \%$ for temperature and relative humidity, respectively.

Table (3) The isolated microorganisms on different media (Cellulose agar, Gelatin agar, Dox agar, and Nutrient agar)

\begin{tabular}{|c|c|c|c|c|}
\hline \multirow{2}{*}{ Swabs site } & \multicolumn{4}{|c|}{ Media used } \\
\hline & Cellulose agar & Gelatin agar & Doxs agar & Nutrient agar \\
\hline Air of showcases & - Asp. Niger & Asp. flavus & Asp. niger & - \\
\hline Showcase 14 & - Pacillomyces carneus & - & Pacillomyces carneus & - \\
\hline Showcase 28 & & - & Pacillomyces carneus & - \\
\hline Showcase 30 & & - & & - \\
\hline Showcase 31 & & - & & - \\
\hline Showcase 133 & & - & & - \\
\hline Showcase 144 & $\begin{array}{l}\text { - Clado. herbarum } \\
\text { - Pacillomyces carneus }\end{array}$ & - & & - \\
\hline
\end{tabular}
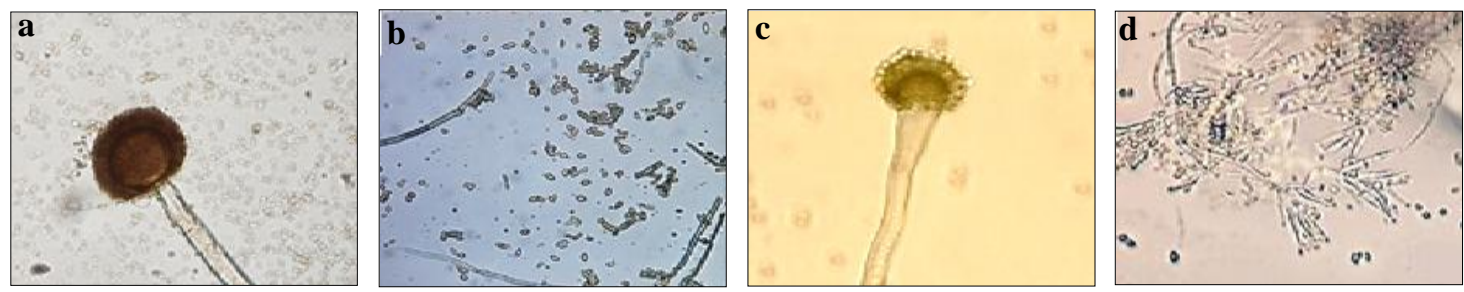

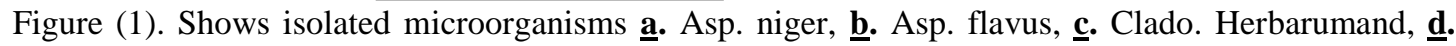
Pacillomyces carneus showing conidia and conidiophores (400X). 


\subsection{Determination of celluloses and protease produced by the isolated microorganisms using cup plate technique}

The resulted data, tab. (4) of the the degree of decomposing protein and tested microorganisms proved that they cell-ulose. The tabulated data show that varied in the ability to produce cellulase Paecilomyces carneus achieved the higand protease enzymes. Thus, they vary in hest cellulytic and proteolytic activities.

Table (4) The ability of the isolated microorganisms to produce cellulases and proteases enzymes

\begin{tabular}{lcc}
\hline \multirow{1}{*}{ Microbial isolates } & \multicolumn{2}{c}{ Diameters of clearing zone (mm) } \\
\cline { 2 - 3 } Asp. niger & Celluloses & Proteases \\
Asp. flavus & 30 & 28 \\
Paecilomyces carneus & 27 & 25 \\
\hline Clado. herbarum & 33 & 30 \\
\hline
\end{tabular}

\subsection{Determination of MIC of antimicrobial agents against the isolated micro- organisms}

In this part of the study, the prepared microcides applied to the isolated fungi to determine the MIC that inhibited each fungal species proved that in the case of Dichloro-xylenol, good response could be detected at all concentration except for $900 \mathrm{ppm}$ that gave no response in all isolates. Therefore, it could be reported that using Di-chloroxylenol at (1000 ppm) gave the diameter of a clear zone ranged (19-22 mm). In the case of sodium azide, no response could be detected at 900 and $1000 \mathrm{ppm}$ concentrations of all isolated microorganisms except for Asp. niger and Asp. Flavus that gave responses at $(1000$ $\mathrm{ppm}$ ) with diameters of 19 and $18 \mathrm{~mm}$, respectively. It could be reported that using Sodium azide at (2000 ppm) gave the diameter of a clear zone ranged (20-

$24 \mathrm{~mm}$ ). P-chloro-m-cresol showed good response at all concentration except for $900 \mathrm{ppm}$ that gave no response in all isolates. Thus, it could be reported that using p-chloro-m-cresol at (1000 ppm) gave the diameter of a clear zone that ranged $(18-21 \mathrm{~mm})$. These data can be used to recommend the best concentrations of a specific microbicide for the biotreatment of infected textile materials by any of the tested fungi. For instance, Di-chloroxylenol at (1000 ppm) is sufficient to inhibit all isolated microorganisms, followed by p-chloro-m-cresol at (1000ppm) and Sodium azide at $(2000$ $\mathrm{ppm})$. These results are listed in table (5) $\&$ shown in fig. (2).

Table (5) Determination of inhibition zone ( $\mathrm{mm}$ ) of fungal species grown on Czapek agar as affected by three microcides; Di-chloroxylenol, Sodium azide and p-chloro-m-cresol (from 900 to 3000 ppm).

\begin{tabular}{lcccccccccccc}
\hline \multirow{1}{*}{ Fungal isolates } & \multicolumn{4}{c}{ Mean diameter of inhibition zone (mm) at different concentrations (ppm) } \\
\cline { 2 - 12 } & \multicolumn{4}{c}{ Di-chloroxylenol } & \multicolumn{4}{c}{ Sodium azide } & \multicolumn{5}{c}{ p-chloro-m-cresol } \\
Asp. niger & 900 & 1000 & 2000 & 3000 & 900 & 1000 & 2000 & 3000 & 900 & 1000 & 2000 & 3000 \\
Asp. flavus & 0 & 22 & 30 & 35 & 0 & 19 & 24 & 28 & 0 & 20 & 25 & 31 \\
Paecillomyces carneus & 0 & 21 & 25 & 28 & 0 & 18 & 22 & 27 & 0 & 19 & 24 & 28 \\
Clado.herbarum & 0 & 20 & 24 & 28 & 0 & 0 & 20 & 25 & 0 & 21 & 27 & 32 \\
& 0 & 19 & 22 & 27 & 0 & 0 & 21 & 24 & 0 & 18 & 23 & 29
\end{tabular}

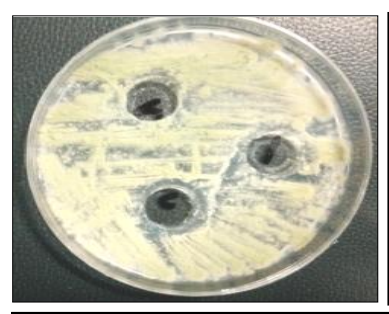

Asp. Flavus

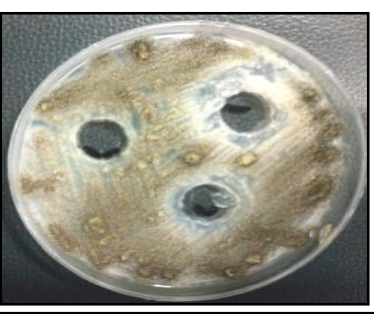

Asp. niger

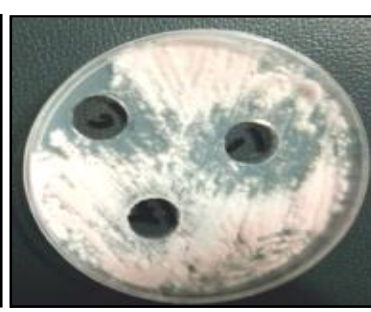

Pas. Carneus

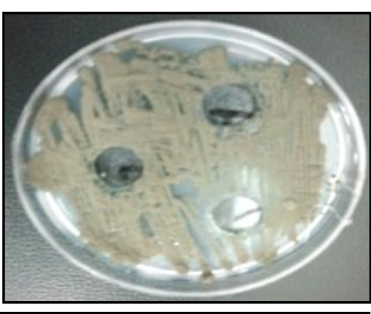

Clado. herbarum

Figure (2) Shows determination of inhibition zone ( $\mathrm{mm}$ ) of fungal isolates grown on Czapek agar 


\subsection{Method of treatment}

The above results illustrated that $\mathrm{Di}$ chloroxylenol can be used as the best antimicrobial at (1000 ppm) concentration to control the deterioration of textile through three methods of application. The first method (direct method) is used to control the infection by a specific brush for cleaning and treatment, the second method (injection method) uses a specific syringe to apply the antimicrobial only on the infected area. In the third method (indirect method), the treatment is applied on the object by fumigation method without contacting the object. Therefore, the third method can be used because it is always safe. In this method, the best antimicrobial is used by dissolving the best MIC of each substance in ethyl alcohol (95\%) and the volume used according to the volume of the showcase containing the pieces of textile.

\subsection{Microcides and their effects on infected textile}

In this experiment, the pieces of infected textile were treated with the best microcides, i.e. Di-chloroxylenol to control their deterioration. The effects of microcides on modern infected pieces of textile before and after the application were determined using Binocular dissecting stereo microscope, FTIR, and ESEM. The results of morphological data obtained by Binocular (26-x) show the penetration of fungal threads into the textile sample, and revealing weakness with individual filaments and dark brown spots. They also proved that, Di-chloroxylenol is the best antim-

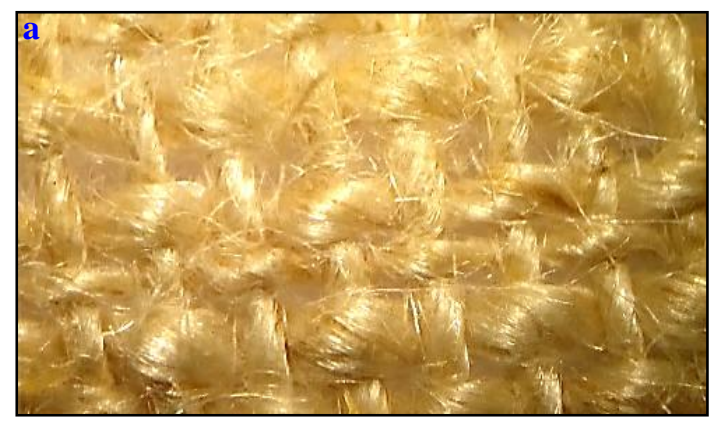

icrobial at (1000 ppm) concentration. There is no clear effect on the properties of test textile as tensile, fig. (3-a,b). Furthermore, tab. (6) shows that significant changes were detected in carbon's percentage varying from $51.24 \%$ to $58.15 \%$ and calcium's increased from $0.61 \%$ to $2.27 \%$. Moreover, the following elements appeared after the infection as a result of partially surface erosion of the object: $\mathrm{Na}(1.81 \%), \mathrm{Mg}$ (0.79\%), Al (0.42\%), P (0.41\%), S $(0.67 \%)$ and $\mathrm{Cl}(1.63 \%)$. Micrographs of linen textile before and after microbial infection are shown in fig. (4-a,b,c,d).

Figure (3) Shows binocular stereo microscope of a. modern linen textile sample before infection (26-x), b. modern linen textile sample (26-x) affected by fungal growth, weakness and fragmentation of fibers after infection for 60 days at room temperature, and treatment with $1000 \mathrm{ppm}$ Di-chloroxylenol.

Table (6) Elemental analysis of modern linen textile sample before and after infection for 2 months.

\begin{tabular}{|c|c|c|c|c|c|c|c|c|c|c|}
\hline \multirow{2}{*}{ Wt \% } & \multicolumn{10}{|c|}{ Analytical Results } \\
\cline { 2 - 12 } & $\boldsymbol{C}$ & $\boldsymbol{O}$ & $\boldsymbol{N a}$ & $\boldsymbol{M g}$ & $\boldsymbol{A l}$ & $\boldsymbol{P}$ & $\boldsymbol{S}$ & $\boldsymbol{C l}$ & $\boldsymbol{C a}$ & Total \\
\hline Before & 51.24 & 48.15 & - & - & - & - & - & - & 0.61 & 100.0 \\
\hline After & 58.15 & 33.86 & 1.81 & 0.79 & 0.42 & 0.41 & 0.67 & 1.63 & 2.27 & 100.0 \\
\hline
\end{tabular}
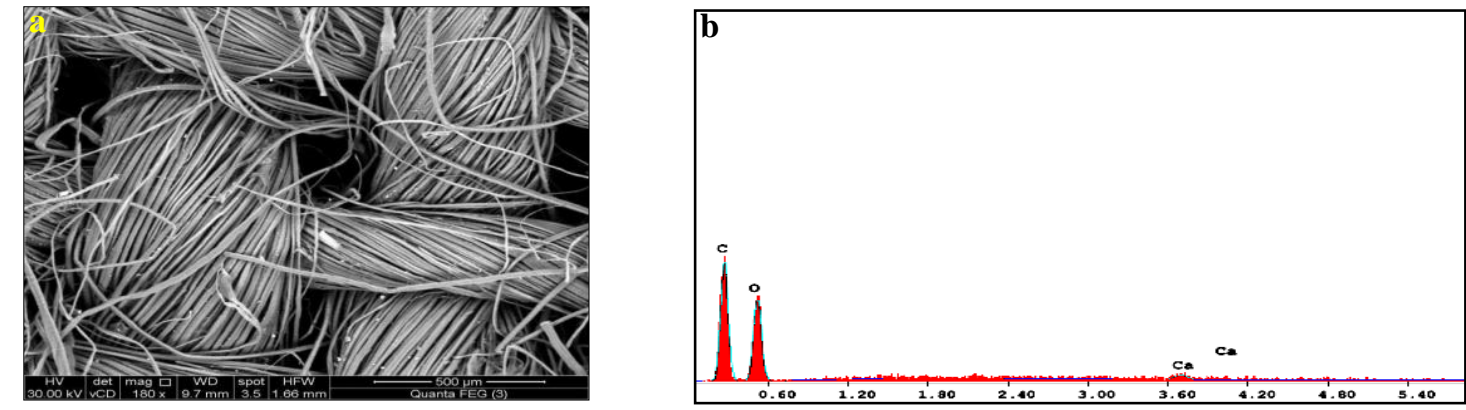

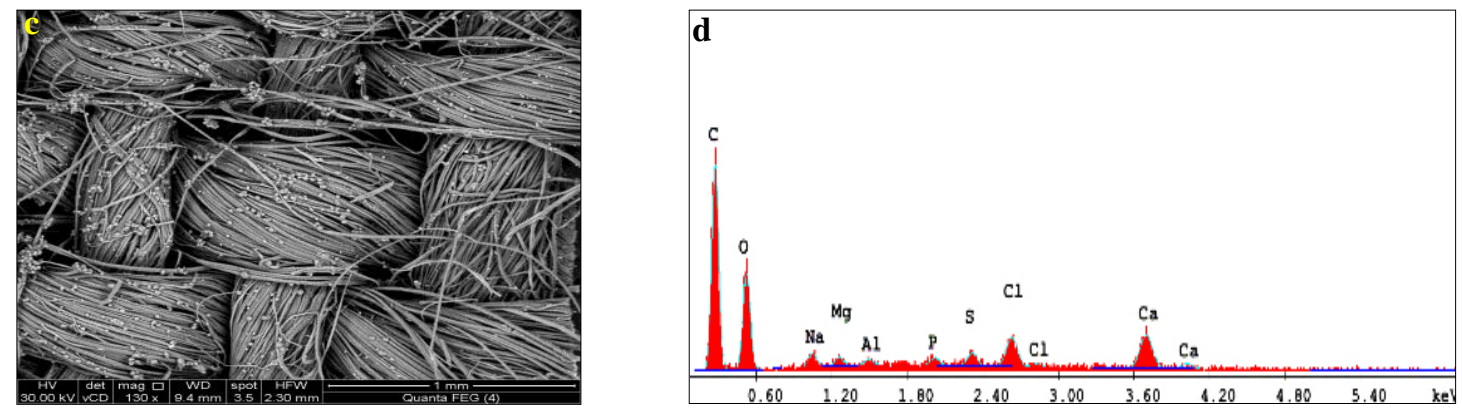

Figure (4) Shows ‥ SEM photomicrograph of a modern linen textile sample before infection (500-x), b. EDX pattern of major elements of a modern linen textile sample before infection, $\underline{\mathbf{c}}$. SEM photomicrograph of a modern infected linen textile sample affected by fungal growth on the surface $(500-x)$, $\underline{\mathbf{d}}$. EDX pattern of major elements of a modern linen textile sample after infection

Through determining the chemical properties of linen by FTIR equipment, it could be noted that there is a net change in dipole moment during the vibration of the molecule or the functional group (specific groups of atoms or bonds among molecules, indicating the characteristic chemical reactions of these molecules) for infrared activity leading to the absorption of infrared radiation. Figure (5) illustrates that the chemical changes within the linen structure are due to microbial infection resulted in the degradation of organic compounds into tiny compounds which have other chemical specific groups. In addition, specific groups of atoms or bonds disappeared within the molecules that are responsible for the characteristic chemical reactions of those molecules.
Furthermore, it indicates that chemical changes inside the linen are due to microbial infection resulted in the degradeation of organic compounds into small compounds (which have another chemical functional groups). Also, it is attributed to the disappearance of other chemical groups and producing substances with $\left(\mathrm{H}^{+}\right)$and $\left(\mathrm{OH}^{-}\right)$groups which changes $\mathrm{pH}$ values of textile samples. In considering the different functional groups in (control) sample without infection against infected sample, the following bands were obtained: hydroxyl group, hydrogen-bonded $\mathrm{O}-\mathrm{H}$ stretching at $v \approx 3300-3500 \mathrm{~cm}^{-1}$, the C-H stretching at $v \approx 2800-3000 \mathrm{~cm}^{-1}$, the $\mathrm{C}-\mathrm{O}$ vibration and stretch linkage at $v$ $\approx 1020-1100 \mathrm{~cm}$.

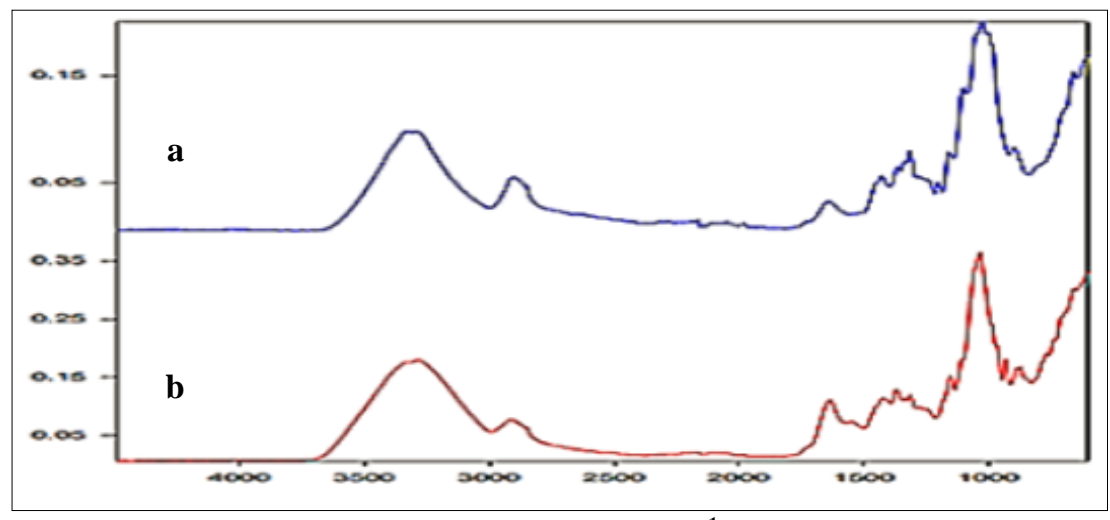

Wave number $\mathrm{cm}^{-1}$

Figure (5) Shows FTIR chart of linen textile sample $\underline{\mathbf{a}}$. before \& $\underline{\mathbf{b}}$. after infection by Asp .flavus

\section{Discussion}

The present study aims to highlight the effect of microbial deterioration on the ancient textile and the best methods to resist it. In addition, some analyses were done too textile samples before and after infection using different perspectives: 
(Stereo microscopes, SEM with EDXS, FTIR, fiber structure, and fiber chemical composition. The microorganisms of six showcases $(14,28,30,31,133 \& 144)$ in the Egyptian Textile Museum; air sample were isolated onto four prepared agar media (Cellulose agar, Gelatin agar, Dox agar, and Nutrient agar), three genera were identified: Aspergillus, Cladosporium and Paecilomyces. Our results illustrate that the genus Paecilomyces carneus was the dominant genus in the six showcases of the total fungal isolates. Also, they indicate the presence of various species of Aspergillus and $A L T$, which agree with those obtained by Abed-EL Hameed, (1999) [18]. In addition the same species "Aspergillus, as well as Alternaria, Cladosporium, Acremonium sp., Epicoccum sp, and Fusarium solani" were isolated from wooden coffins at the Egyptian Museum [19]. The isolated microorganisms were tested to produce the cellulase and protease enzymes. The tabulated data show the highest catalytic and proteolytic activities were observed by Paecilomyces canoes. These data match those obtained by Pekhtasheva, et al., 2012 [20] proving that during the bio-deterioration of ancient textiles, microorganisms produce extracellular cellulalytic and proteolysis enzymes, as well as secreting pigments and acids. Furthermore, assimilation-micro-organisms use fibers as a nutrient source; and/or degradationfabrics are damaged due to the growth of microorganisms and secreted metabolites. Additionally, it could be argued that Cheatomium, Myrothecium, Stachbotrys, Vertcillium, Alternaria, Pen-icillium, and Aspergillus as fungal genera are the most active microorganisms that involve in the degradation of cellulose fabrics, especially the two last genera [21]. The results of tested microcides, Di-chloroxylenol, Sodium azide and p-chloro-m-cresol (from 900 to $3000 \mathrm{ppm}$ ) show that Di-chloroxylenol reported good response at (1000 ppm) concentration giving the diameter of a clear zone range of $(19-22 \mathrm{~mm})$ in all isolates. In the case of Sodium azide, a good response was shown at $(2000$ $\mathrm{ppm})$ concentration giving the diameter of a clear zone range of $(20-24 \mathrm{~mm})$ in all isolates. In case of p-chloro-m-crucial good response was reported in concentration $1000 \mathrm{ppm}$ gave the diameter of clear zone ranged from $18-21 \mathrm{~mm}$ in all isolates. All the previous data can be utilized to recommend the best concentrations of a specific microbicide for the bio-treatment of infected textile materials. Di-chloroxylenol at $(1000 \mathrm{ppm})$ concentrations was sufficient to inhibit all isolated microorganisms, followed by p-chloro-m-cresol at (1000 ppm), and Sodium azide at (2000 ppm). In a similar study, it could be asserted that dichlorophen is sufficient for the treatment of the textile sample to completely prevent fungal growth and was the least harmful to the textile in the Golestan Museum of Iran [22]. Additionally, it could be attested that the third method "indirect method applied the treatment on the object by fumigation" is the best one to apply the antimicrobial by dissolving the best MIC of each substance in ethyl alcohol (95\%) and the volume used according the volume of the showcase holding the pieces of textile. These results agree with those obtained by Kakoauei, et al., (2014) in similar case [23], where, they show that fumigation techniques are the suitable method for inactivation of Bacillus anthracis strain spores with methyl bromide (MB). Regarding the evaluation processes of microcides on modern infected textile pieces by different techniques; the morphological data obtained by binocular, fig. (3) show the penetration of fungal threads into textile sample revealing weakness with individual filaments and dark brown spots. The results of ESEM investigation, fig. (4-a, c) shows significant changes were detected in carbon's percentage varying from 51.24 to $58.15 \%$ and calcium's percentage increased from 0.61 to $2.27 \%$. In addition, appearing of the elements sodium (1.81), magnesium $(0.79 \%)$, aluminum $(0.42 \%)$, phosphorus $(0.41 \%)$, sulfur $(0.67 \%)$ and chloride (1.63\%), tab. (6) \& fig. (4-b,d) after infection is attributed essentially to the partially surface erosion of the object. Similar findings were previously reported and interpreted by Gadd (2004) 
[24] and Abdel-Kareem, (2010) [25]. They proved that fungal abilities to penetrate into the material by hyphal growth and lead to mechanical deterioration of the object. In addition, they leads to biocorrosive activity due to excretion of organic acids or oxidation of mineral cations [26,27]. Also, it could be said that the fungal growth on the object's surface can also alter these surfaces due to their metabolism. This process finally lead to the generating of organic acids (oxalic acid and citric acid) that have chelating properties by weakening the metal oxygen bond, increasing the solubility of some metals, and forming complexes with the mineral cations present on the surface matrix [28-31]. Finally, it could be asserted that the chemical changes within the linen structure due to microbial infection lead to the degradation of organic compounds into tiny compounds (which have other chemical specific groups). Also, disappearance of specific groups of atoms or bonds within molecules is responsible for the characteristic chemical reactions of those molecules. In considering the different functional groups in (control) sample without infection against the infected sample, fig. (5) the following bands were obtained: hydroxyl group, hydrogen-bonded $\mathrm{O}-\mathrm{H}$ stretching at $v \approx 3300-3500$ $\mathrm{cm}^{-1}$, the C-H stretching at $v \approx 2800-3000$ $\mathrm{cm}^{-1}$, the $\mathrm{C}-\mathrm{O}$ vibration and stretch linkage at $v \approx 1020-1100 \mathrm{~cm}$. as have been argued previously similar studies, attenuated total reflectance Fourier transform infrared (ATR-FTIR) spectroscopy was used to detect microbial metabolic products on carbonate mineral surfaces following Escherichia coli growth Heather, et al., (2008) [32] and Serre, et al., (2015) [33].

\section{Conclusion}

Ancient textile materials exposed to microbial deterioration. Under unfavorable conditions of high humidity and temperature. The most common microorganisms isolated from archaeological textiles are molds. The isolated microorganisms have the ability to produce cellulases and protease enzymes, which gave negative effects on the textile. Treatment of infected textile with Di-chloroxylenol as best antimicrobial at concentration 1000 ppm gave good results in controlling the infection and showed no changes in physical, morphological and mechanical properties of the infected textile.

\section{Acknowledgments}

The authors express their sincere thanks and gratitude to the staff members of the Egyptian Textile Museum, Cairo for their kind assistance and cooperation.

\section{References}

[1] Allsopp, D., Seral, K. \& Gaylarde, C., (2004). Introduction to Biodeterioration, $2^{\text {nd }}$ ed., Cambridge Univ. Press, London.

[2] Capitelli, F., Fermo, P., Vechi, R., Piazzalunga, A., Valli, G., Zanardini, E. \& Sorlini, C., (2009). Chemicalphysical and microbiological measurements for indoor air quality assessment at the CA' Granda Historical Archive, Milan (Italy), J. of Water, Air and Soil Pollution, Vol. 201 (1-4), pp: 109-120.

[3] Abdel-Kareem, O., (2010). Monitoring, controlling and prevention of the fungal deterioration of textile artifacts in the museum of Jordanian Heritage, $M A A$, Vol. 10 (2), pp: 85-96.

[4] Florian, M., (1997). Heritage Eaters: Insects and Fungi in Heritage Collections, James \& James Scie. Pub. Ltd., London.

[5] Heckscher, M., (2008). Creating park, The Metropolitan Museum of Art, USA

[6] Szostak-Kotowa, J., (2004). Biodeterioration of textiles, Int. Biodeterioration \& Biodegradation, Vol. 53 (3), pp: 165-170.

[7] Karadag, R., (2014). Some nondestructive and micro-analytical methods for the conservation on textiles from 
cultural heritage, in: Museen der Stadt Wien - Stadtarchäologie (ed.) Proc. of the $19^{\text {th }}$ Int. Conf. on Cultural Heritage and New Technologies (CHNT19-2014), Vienna, pp: 1-12.

[8] Balazsy, A. \& Eastop, D., (1998). Chemical principles of textile conservation, $1^{\text {st }}$ ed., Butterworth Heinemann Series in Conservation and Museology; Plant a Tree: Oxford.

[9] Gutarowska, B. \& Pietrzak. K., (2017). Historical textiles-a review of microbial deterioration analysis and disinfection methods, Textile Research J., Vol. 87 (19), pp: 2388-2406.

[10] Cowan, S.T., (1974). Cowan and steel's manual for the identification of medical bacteria, $2^{\text {nd }}$ ed. Cambridge Univ Press, London.

[11] Ammar, M., Desouki, E., ElHouseiny, M. \& Sedki, N., (1995). Some environmental and nutritional parameters controlling the productivity of cellulose by Trichoderma hamatum and T. longibrachaitum. AlAzhar Bulletin of Science, Vol. 6 (1), pp: 423-437.

[12] Reinprecht, L. \& Kizlink, J. (2007) Wood preservatives prepared from electrical and cooling wastes. Acta Facultatis Ecologiae TU Zvolen, Vol. 15, pp: 71-76.

[13] Gilman, J., (1974). A manual of soil fungi, $2^{\text {nd }}$ ed., Iowa State Univ. Press, USA.

[14] Domsch, K., Gams, W. \& Anderson, T., (1980a). Compendium of soil fungi, Vol. 1, Academic Press, London.

[15] Domsch, K., Gams, W. \& Anderson, T., $\left(1980_{\mathrm{b}}\right)$. Compendium of soil fungi, Vol. 2, Academic Press, London.

[16] Brantner, A., Peiffer, K. \& Green, E., (1993). Antibacterial assays of the pharmacopoeias: diffusion tests of natural substances and their evaluation. J. Planta MED, Vol. 59 (7), pp: 675-680.

[17] Mansour, M., Abdel-Megeed, A., Nasser, R., Salem, M., (2015) Comparative evaluation of some woody trees methanolic extracts and Paraloid B-72 against phytopathogenic mold fungi Alternaria tenuissima and Fusarium culmorum. BioResources, Vol. 10, pp: 2570-2584.

[18] Erra, P. \& Gomez., N., (1996). FTIR analysis to study chemical changes in wool following a sulfiteolysis treatment, Textile Research J., Vol. 67 (6), pp: 397-401.

[19] Gutarowska, B. \& Pietrzak. K., (2017). Historical textiles-a review of microbial deterioration analysis and disinfection methods, Textile Research J., Vol. 87 (19), pp: 23882406.

[20] Balta, Z. \& Demetrescu, I., (2017). ATR/FTIR investigation into the nature of the metal threads from Roman medieval textile, University Politechnica of Bucharst Scientific Bulletin Series-C Electrical Engineering and Computer Science, Vol. 79 (2), pp: 25-36.

[21] Szostak-Kotowa, J., (2004). Biodeterioration of textiles, Int. Biodeterioration \& Biodegradation, Vol. 53 (3), pp: 165-170.

[22] Kowalik, R., (1980). Micro biodeterioration of library materials, Part 2, Micro decomposition of basic organic materials. Restaurateur, Vol. 4 (34): pp: 135-219.

[23] Kakoauei, M., Kakouei, E. \& Kumaran, S., (2014). History, technology, and treatment of a painted silk folding screen belonging to the palacemuseum of Golestan in Iran, Fibers and Textiles in Eastern Europe, Vol. 22 (104), pp: 69-75.

[24] Warscheid, T. \& Brahms, J., (2000). Influence of atmospheric pollutants on deterioration of stone. Int. Biodeter-ioration \& Biodegradation, Vol. 45 (2), pp:35-42.

[25] Ljaljević-Grbić, M. \& Vukojević, J., (2009). Role of fungi in biodeterioration process of stone in historic buildings, Proc. Nat. SCI. Matica Srpska Novi Sad,Vol. 116, pp: 245251. 
[26] Gómez-Alarcón, G., Munoz, M., Arino, X. \& Ortega-Calvo, J., (1995a). Microbial communities in weathered sandstones: The case of Carrascosa del Campo church, Spain. The Science of the Total Environment, Vol. 167, pp: 249-254.

[27] Ljaljeviã-Grbiã, M. \& Stupar., M., (2013). Molds in museum environments: Biodeterioration of art photographs and wooden sculptures, Archives of Biological Sciences, Vol. 65 (3), pp: 955-962.

[28] Harley, A. \& Gilkes, R., (2000). Factors influencing the release of plant nutrient elements from silicate rock powders: A geochemical overview. Nutrient Cycling in Agroecosystems, Vol. 56, pp: 11-36.

[29] Gómez-Alarcón, G., Munoz, M. \& Flores, M., (1995b). Excretion of organic acids by fungal strains isolated from decayed sandstone. Int. Biodeter-ioration \& Biodegradation, Vol. 34, pp: 169-180.
[30] Gadd, G., (2004). Mycotransformation of organic and inorganic substrates, Mycologist, Vol. 18 (2), pp: 60-70.

[31] Abdel-Kareem, O., (2010). Fungal deterioration of historical textiles and approaches for their control in Egypt, e-Preservation Science, Vol. 7, pp: 40-47.

[32] Heather, A., Stuart, A., Ariel, F., Nicholas, M. \& Hazel, A., (2008). Use of attenuated total reflectance Fourier Transform Infrared spectroscopy to identify microbial metabolic products on carbonate mineral surfaces, Applied and Environmental Microbiology, Vol. 74(14), pp: 4553-4559.

[33] Serre, S., Mickelsen, L., Calfee, M., Wood, J., Gray, M., Scheffrahn, R., Perez, R. Kern, W. \& Daniell, N., (2015). Whole-building decontamination of Bacillus anthracis sterne spores by methyl bromide fumigation, J. of Applied Microbiology, Vol. 120, pp: 80-89. 